\title{
Neoplastic fever in patients with bone and soft tissue sarcoma
}

\author{
TOMOKI NAKAMURA, AKIHIKO MATSUMINE, TAKAO MATSUBARA, \\ KUNIHIRO ASANUMA and AKIHIRO SUDO
}

\begin{abstract}
Department of Orthopaedic Surgery, Mie University Graduate School of Medicine, Tsu, Mie 514-8507, Japan
\end{abstract}
Received January 28, 2016; Accepted August 2, 2016

DOI: $10.3892 / \operatorname{mco} .2016 .1027$

\begin{abstract}
The development of fever is a common complication in the clinical course of cancer. If all other potential causes of fever are excluded, the possibility of neoplastic fever should be considered. The aim of the present study was to determine the incidence of neoplastic fever in patients with bone and soft tissue sarcomas. Between January 2009 and December 2014, 195 patients with bone and soft tissue sarcoma (111 men and 84 women; mean age, 55 years) were admitted to the Department of Orthopaedic Surgery of Mie University Graduate School of Medicine (Tsu, Japan). Episodes of fever were observed in 58 patients (30\%), of whom $11(5.5 \%)$ had neoplastic fever (mean maximum temperature, $38.9^{\circ} \mathrm{C}$ ). The causes of neoplastic fever were as follows: Primary tumor $(n=3)$, local recurrence $(n=1)$, metastasis $(n=5)$, and local recurrence with metastasis $(n=2)$. Of the 11 patients, 9 were treated with naproxen and 8 exhibited a complete response, with their temperature normalizing to $<37.3^{\circ} \mathrm{C}$ within $24 \mathrm{~h}$. The 2 patients who were not treated with naproxen underwent surgical tumor resection, which resulted in prompt and complete lysis of the fever. In conclusion, neoplastic fever occurred in 5.5\% of the 195 patients with bone and soft tissue sarcomas investigated herein. Naproxen may be effective for treating neoplastic fever in patients with bone and soft tissue sarcoma; however, radical tumor treatment may have to be considered to achieve permanent lysis of the fever.
\end{abstract}

\section{Introduction}

The development of fever is a common complication in the clinical course of cancer (1-4). It is crucial to determine the origin of fever, as patients are managed differently depending on the cause. Neutropenic fever is a common occurrence in patients with neutropenia after intensive chemotherapy (1-3). Neutropenic fever reportedly occurs in $37 \%$ of patients with osteosarcoma (5), 17-26\% of patients with Ewing's sarcoma (6)

Correspondence to: Dr Tomoki Nakamura, Department of Orthopaedic Surgery, Mie University Graduate School of Medicine, 2-174 Edobashi, Tsu, Mie 514-8507, Japan

E-mail: tomoki66@clin.medic.mie-u.ac.jp

Key words: neoplastic fever, naproxen, soft-tissue sarcoma, bone sarcoma and 8-54 of those with soft tissue sarcoma (7-9). Furthermore, patients with bone and soft tissue sarcomas are at risk of surgical site infection, which was reported to occur in 6-15\% of those patients who undergo surgery (10-12). Even in the absence of surgical site infection and neutropenia, febrile complications often develop $(1-4,13,14)$. Fever may be caused by diagnostic and/or therapeutic procedures, including medications, transfusions, surgical procedures, hematoma and thrombosis $(1-4,13,14)$. If all the potential causes of fever are excluded, the possibility of neoplastic fever should be considered $(13,15,16)$. Neoplastic fever is a paraneoplastic syndrome that is encountered in $5 \%$ of cancer patients (17). There have been a few case reports on neoplastic fever among patients with bone and soft tissue sarcomas (18-20). The purpose of the present study was to investigate the occurrence of febrile episodes defined as neoplastic fever in patients with bone and soft tissue sarcomas during treatment and follow-up.

\section{Patients and methods}

Subjects. Between January 2009 and December 2014, 195 patients with bone and soft tissue sarcomas were admitted to the Department of Orthopaedic Surgery of Mie University Graduate School of Medicine (Tsu, Japan). Patients who were diagnosed based on biopsy results alone and those who were admitted for best supportive care without surgical resection, chemotherapy and/or radiotherapy, were excluded. The study cohort comprised 111 men and 84 women with a mean age of 55 years. The primary sarcoma originated from the soft tissue in 147 patients and from the bone in 48 patients. The main histological diagnoses of malignant bone tumors were osteosarcoma $(n=24)$, chondrosarcoma $(n=10)$ and Ewing's sarcoma $(n=8)$, while the main histological diagnoses of soft tissue sarcomas were well-differentiated liposarcoma $(n=33)$, myxofibrosarcoma $(n=21)$, undifferentiated pleomorphic sarcoma $(n=19)$ and leiomyosaroma $(n=16)$. Surgical resection for the primary tumor was performed in 158 patients and for recurrence or metastasis in 17 patients. During the clinical course, chemotherapy and radiation therapy were administered to 55 and 50 patients, respectively.

Diagnosis. Neoplastic fever was diagnosed according to the following criteria: i) A single temperature measurement of $>38.3^{\circ} \mathrm{C}\left(101^{\circ} \mathrm{F}\right)$ or a temperature of $>38.0^{\circ} \mathrm{C}\left(100.4^{\circ} \mathrm{F}\right)$ sustained for $>1 \mathrm{~h}(21)$, ii) duration of fever for $72 \mathrm{~h}$, iii) no evidence of infection on clinical and laboratory 
Table I. Characteristics of patients with neoplastic fever.

\begin{tabular}{|c|c|c|c|c|c|c|}
\hline Age/gender & Diagnosis & Cause of fever & $\begin{array}{l}\text { Maximum } \\
\text { temp }\left({ }^{\circ} \mathrm{C}\right)\end{array}$ & $\begin{array}{c}\text { IL-6 } \\
(\mathrm{pg} / \mathrm{ml})^{\mathrm{a}}\end{array}$ & $\begin{array}{l}\text { Naproxen } \\
\text { treatment }\end{array}$ & $\begin{array}{l}\text { Treatment } \\
\text { for tumors }\end{array}$ \\
\hline $26 / \mathrm{F}$ & Clear cell sarcoma & Lymph mets & 39.6 & 209 & Yes & None \\
\hline $13 / \mathrm{F}$ & Osteosarcoma & LR and lung mets & 39.6 & NA & No & Op \\
\hline $46 / \mathrm{M}$ & Ewing's sarcoma & Primary tumor & 38.6 & NA & Yes & $\mathrm{Op}, \mathrm{Cx}$ \\
\hline $16 / \mathrm{M}$ & Osteosarcoma & Primary tumor & 39.0 & 34.8 & Yes & $\mathrm{Op}, \mathrm{Cx}$ \\
\hline 26/M & Ewing's sarcoma & Lung mets & 39.0 & NA & Yes & $\mathrm{Cx}$ \\
\hline $72 / \mathrm{F}$ & Leiomyosarcoma & Pelvic mets & 38.5 & NA & Yes & None \\
\hline $24 / F$ & Epithelioid sarcoma & LR and lung mets & 39.1 & NA & Yes & None \\
\hline $61 / \mathrm{M}$ & Leiomyosarcoma & Stomach mets & 38.3 & NA & No & $\mathrm{Op}, \mathrm{Cx}$ \\
\hline $42 / \mathrm{F}$ & UPS of bone & Lung and pancreas mets & 39.2 & 16.7 & Yes & $\mathrm{Cx}$ \\
\hline $81 / \mathrm{F}$ & MPNST & LR & 39.0 & 34.4 & Yes & Op \\
\hline $71 / \mathrm{F}$ & Fibrosarcoma & Primary tumor & 38.7 & 219 & Yes & Op \\
\hline
\end{tabular}

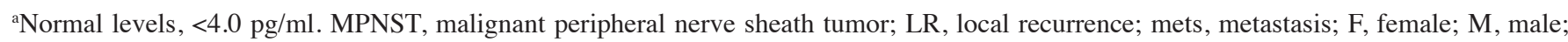
UPS, undifferentiated pleomorphic sarcoma; Op, operation; Cx, chemotherapy; temp, temperature; IL, interleukin; NA, not available.

Table II. Characteristics of patients who received naproxen treatment.

\begin{tabular}{|c|c|c|c|c|c|c|c|}
\hline \multirow[b]{2}{*}{$\begin{array}{l}\text { Age/ } \\
\text { gender }\end{array}$} & \multicolumn{2}{|c|}{ Prior to naproxen } & \multirow{2}{*}{$\begin{array}{c}\text { Dose of } \\
\text { naproxen } \\
\text { (mg/day) }\end{array}$} & \multirow[b]{2}{*}{$\begin{array}{c}\text { Response to } \\
\text { naproxen }\end{array}$} & \multicolumn{2}{|c|}{3 days after naproxen } & \multirow{2}{*}{$\begin{array}{c}\text { Duration of } \\
\text { naproxen } \\
\text { treatment } \\
\text { (weeks) }\end{array}$} \\
\hline & $\begin{array}{l}\text { WBC } \\
\left(/ \mathrm{mm}^{3}\right)\end{array}$ & $\begin{array}{c}\text { CRP } \\
(\mathrm{mg} / \mathrm{dl})\end{array}$ & & & $\begin{array}{c}\text { WBC } \\
\left(/ \mathrm{mm}^{3}\right)^{\mathrm{a}}\end{array}$ & $\begin{array}{c}\text { CRP } \\
(\mathrm{mg} / \mathrm{dl})^{\mathrm{b}}\end{array}$ & \\
\hline $26 / \mathrm{F}$ & 10,350 & 11.48 & 300 & No & 10,610 & 22.55 & 2 \\
\hline 46/M & 3,870 & 5.52 & 400 & Yes & 3,790 & 7.12 & 4 \\
\hline $16 / \mathrm{M}$ & 11,000 & 14.83 & 300 & Yes & 6,140 & 4.26 & 3 \\
\hline $26 / \mathrm{M}$ & 8,180 & 13.07 & 400 & Yes & 4,090 & 12.85 & 1 \\
\hline $72 / \mathrm{F}$ & 10,640 & 9.95 & 400 & Yes & 15,200 & 13.28 & 3 \\
\hline $24 / F$ & 11,120 & 9.8 & 300 & Yes & 8,720 & 8.27 & 3 \\
\hline $42 / \mathrm{F}$ & 5,030 & 24.84 & 300 & Yes & 3,320 & 18 & 6 \\
\hline $81 / \mathrm{F}$ & 8,800 & 14.34 & 300 & Yes & 7,410 & 8.05 & 1 \\
\hline $71 / \mathrm{F}$ & 4,190 & 16.82 & 600 & Yes & 4,430 & 20.46 & 2 \\
\hline
\end{tabular}

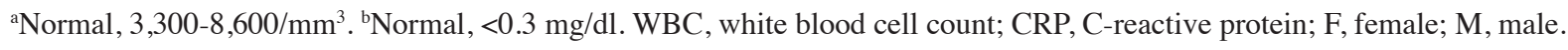

examinations, including blood ( \pm urine and sputum) culture and iv) no evidence of infection on enhanced computed tomography $(10,14)$. Informed consent was obtained from all the patients included in this study.

Statistical analysis. The statistical association of the blood examinations was evaluated using the paired Student's t-test. $\mathrm{P}<0.05$ was considered to indicate statistically significant differences. The Stat View statistical software package, version 5.0 (SAS Institute, Cary, NC, USA) was employed for analysis.

\section{Results}

Patients. Episodes of fever were observed in 58 of the 195 patients $(30 \%)$, of whom 11 were determined as having neoplastic fever (Table I). These patients included 4 men and 7 women, with a mean age of 44 years. The tumor sites responsible for the development of neoplastic fever were as follows: Primary tumor $(n=3)$; local recurrence $(n=1)$; metastasis $(n=5)$; and local recurrence with metastasis $(n=2)$. The mean of the maximum temperature in the 11 patients was $38.9^{\circ} \mathrm{C}$ (range: $38.3-39.6^{\circ} \mathrm{C}$ ).

Treatment and outcome. Of the 11 patients, 9 were treated with naproxen, as complete lysis of fever was not achieved in 8 patients who received loxoprofen and 1 patient who received acetaminophen (Table II). Naproxen was orally administered at a dose of 300-600 mg per day. Prior to the administration of naproxen, the white blood cell count ranged from 3,870 to $11,120 / \mathrm{mm}^{3}$ (mean, $8,131 / \mathrm{mm}^{3}$ ) and the C-reactive protein (CRP) levels ranged from 5.52 to $24.84 \mathrm{mg} / \mathrm{dl}$ (mean, $13.4 \mathrm{mg} / \mathrm{dl}$ ). The serum interleukin-6 (IL-6) level was measured and found to be elevated in 5 of the 11 patients 
(normal, $<4.0 \mathrm{pg} / \mathrm{ml}$; Table I). Of the 9 patients, 8 achieved a complete response with naproxen, with their temperature normalizing to $<37.3^{\circ} \mathrm{C}$ within $24 \mathrm{~h}$. Subsequently, 4 of the 9 patients underwent tumor resection. Further naproxen treatment was not required for these 4 patients after surgery, as they did not develop fever. One of the 9 patients achieved a complete response with chemotherapy (ifosfamide, $12 \mathrm{~g} / \mathrm{m}^{2}$ ) and did not require naproxen as there was no fever. In one patient, it was necessary to reduce the dose of naproxen from 300 to $200 \mathrm{mg}$ per day, as the patient exhibited renal function decline and had no response to naproxen; after 2 months, the patient succumbed to peritoneal metastases without recovering from the fever. Naproxen treatment was continued in the 3 remaining patients, until eventually they succumbed to their disease.

The 2 patients who were not treated with naproxen underwent surgical tumor resection and showed prompt and complete lysis of the fever.

Three days after the administration of naproxen, the white blood cell count varied from 3,320 to $15,200 / \mathrm{mm}^{3}$ (mean, 7,079/. $\mathrm{mm}^{3}$ ) and the CRP levels varied from 4.26 to $22.55 \mathrm{mg} / \mathrm{dl}$ (mean, $12.76 \mathrm{mg} / \mathrm{dl}$ ). There was no significant difference between the mean white blood cell count or the mean CRP levels prior to and after the administration of naproxen $(\mathrm{P}=0.29$ and 0.78 , respectively).

At the time of final review (February, 2016) 1 patient remained alive without disease, whereas 10 patients had succumbed to their disease.

\section{Discussion}

The present study assessed the incidence of neoplastic fever during the clinical course of bone and soft tissue sarcoma patients.

Neoplastic fever, which is defined as fever caused by cancer itself, has been shown to be the most common cause of fever of unknown origin in cancer patients, particularly lymphoma and leukemia patients $(13,14,17)$. Neoplastic fever is relatively rare in patients with bone and soft tissue sarcomas, with only few cases reported to date (18-20,22). In the present study, neoplastic fever occurred in 11 of 195 patients with bone and soft tissue sarcomas (5.5\%). Browder et al (17) reported that $30 \%$ of cancer patients develop fever, and that in $5 \%$ of the patients, the fever has no explanation other than paraneoplastic syndrome. Thus, neoplastic fever should be considered when all other possible causes of fever are excluded. Neoplastic fever often affects the patients' quality of life and may necessitate antipyretic treatment. The antipyretic effect of corticosteroids on neoplastic fever was compared to that of naproxen (23), and it was noted that naproxen treatment resulted in complete lysis of the fever in $90 \%$ of febrile patients; by contrast, complete lysis of fever was only achieved in $50 \%$ of the patients who were treated with corticosteroids. Although the patient number was limited and the design of the study was retrospective, the authors concluded that naproxen was more effective for the treatment of neoplastic fever compared with corticosteroids (23).

To the best of our knowledge, there have been no reports on the effect of naproxen on neoplastic fever in patients with bone and soft tissue sarcomas to date. In the present study, naproxen was administered to 9 of the 11 patients with neoplastic fever; 8 of the 9 patients exhibited a complete response, with their body temperature normalizing to $<37.3^{\circ} \mathrm{C}$ within $24 \mathrm{~h}$. Thus, naproxen may be effective for treating neoplastic fever in patients with bone and soft tissue sarcoma prior to radical treatment or during best supportive care. There was no significant change in the white blood cell count or the CRP levels prior to and after naproxen treatment. There are several possible mechanisms for the production of inflammatory markers, such as CRP and IL-6 (24-26). Tumor growth may cause tissue inflammation (24). Tumor-associated mononuclear cells may produce IL-6 as an immune cytokine response to tumor growth (25). Cancer cells may increase the production of inflammatory proteins (26). Tumor growth cannot be reduced by naproxen; therefore, radical tumor treatment is required to improve these hematological abnormalities. Although there were no complications in the cases presented in this study, naproxen should be used with caution as it has been associated with platelet dysfunction and gastrointestinal side effects (27). Furthermore, the antipyretic effect of other non-steroidal anti-inflammatory drugs on neoplastic fever may be comparable to those of naproxen. A randomized trial including 48 cases reported that indomethacin and diclophenac sodium were equally effective regarding their antipyretic properties, whereas naproxen had the most rapid effect (28). A large-scale study is required to confirm these findings.

The present study had certain limitations. First, although outpatients were referred to our hospital if they exhibited persistent symptoms, we were unable to estimate the episodes of fever occurring among outpatients. Another limitation of the present study is its retrospective nature. However, the present study expands the knowledge on the epidemiology and outcome of neoplastic fever in patients with bone and soft tissue sarcomas.

In conclusion, neoplastic fever occurred in $5.5 \%$ of the 195 patients with bone and soft tissue sarcomas. Naproxen may be effective for treating neoplastic fever in such patients; however, radical tumor treatment may have to be considered to achieve complete and continuous fever lysis without using any antipyretic drugs.

\section{References}

1. Toussaint E, Bahel-Ball E, Vekemans M, Georgala A, Al-Hakak L, Paesmasns M and Aoun M: Cause of fever in cancer patients (prospective study over 477 episodes). Support Care Cancer 14: 763-769, 2006.

2. Nachman JB and Honig GR: Fever and neutropenia in children with neoplastic disease: An analysis of 158 episodes. Cancer 45: 407-412, 1980

3. Pagano L, Caira M, Rossi G, Tumbarello M, Fanci R, Garzia MG, Vianelli N, Filardi N, De Fabritiis P, Beltrame A, et al: A prospective survey of febrile events in hematological malignancies. Ann Hematol 91: 767-774, 2012.

4. Park S, Kang CI, Chung DR, Peck KR, Kim WS and Kim SJ: Clinical significance of non-neutropenic fever in the management of diffuse large B-cell lymphoma patients treated with rituximab-CHOP: Comparison with febrile neutropenia and risk factor analysis. Cancer Res Treat 47: 448-457, 2015.

5. Bacci G, Ferrari S, Longhi A, Picci P, Mercuri M, Alvegard TA, Saeter G, Donati D, Manfrini M, Lari S, et al: High-dose ifosfamide in combination with high-dose methotrexate, adriamycin and cysplatin in the neoadjuvant treatment of extremity osteosarcoma: Preliminary results of an Italian Sarcoma Group/Scandinavian Sarcoma Group pilot study. J Chemother 14: 198-206, 2002. 
6. Lewin J, Wieringa S, Collins M, Desai J, Orme L, Lingaratnam S and Thomas DM: Intra-patient dose escalation in Ewing's sarcoma treated with vincristine, doxorubicin, cyclophosphamide alternating with ifosfamide and etoposide: A retrospective review. Clin Sarcoma Res 3: 15, 2013.

7. Schmitt T, Lehner B, Kasper B, Bischof M, Roeder F, Dietrich S, Dimitrakopoulou-Strauss A, Strauss LG, Mechtersheimer G, Wuchter P, et al: A phase II study evaluating neo/adjuvant EIA chemotherapy, surgical resection and radiotherapy in high-risk soft tissue sarcoma. BMC Cancer 11: 510, 2011.

8. Kalofonos HP, Kourousis C, Karamouzis MV, Iconomou G, Tsiata E, Tzorzidis F, Megas P, Lambiris E and Georgoulias V: A phase II study of docetaxel and epirubicin in advanced adult soft tissue sarcomas (STS). Sarcoma 8: 129-133, 2004.

9. Judson I, Verweij J, Gelderblom H, Hartmann JT, Schöffski P, Blay JY, Kerst JM, Sufliarsky J, Whelan J, Hohenberger P, et al: Doxorubicin alone versus intensified doxorubicin plus ifosfamide for first-line treatment of advanced or metastatic soft-tissue sarcoma: A randomised controlled phase 3 trial. Lancet Oncol 15: 415-423, 2014.

10. Morii T, Mochizuki K, Tajima T, Ichimura S and Satomi K Surgical site infection in malignant soft tissue tumors. J Orthop Sci 17: 51-57, 2012.

11. Nakamura T, Matsumine A, Matsubara T, Asanuma K, Uchida A and Sudo A: Clinical characteristic of patients with large and deep soft tissue sarcomas. Oncol Lett 10: 841-844, 2015.

12. Nakamura T, Matsumine A, Uchida A, Kawai A, Nishida Y, Kunisada T, Araki N, Sugiura H, Tomita M, Yokouchi M, et al: Clinical outcomes of Kyocera Modular Limb Salvage System after resection of bone sarcoma of distal part of the femur: The Japanese Musculoskeletal Oncology Group Study. Int Orthop 38: 825-830, 2014.

13. Zell JA and Chang JC: Neoplastic fever: A neglected paraneoplastic syndrome. Support Care Cancer 13: 870-877, 2005.

14. Dinarello CA and Bunn PA Jr: Fever. Semin Oncol 24: 288-298, 1997.

15. Chang JC and Gross HM: Neoplastic fever responds to the treatment of an adequate dose of naproxen. J Clin Oncol 3: $552-558,1985$

16. Johnson M: Neoplastic fever. Palliat Med 10: 217-224, 1996.

17. Browder AA, Huff JW and Petersdorf RG: The significance of fever in neoplastic disease. Ann Intern Med 55: 932-942, 1961.

18. Osaka S, Fujimoto Y, Yamazaki H, Suzuki K, Sawada S and Hayashi N: Interleukin-1 alpha producing synovial sarcoma with prolonged fever: A case report. Jpn J Clin Oncol 28 : 436-440, 1998.
19. Hamada T, Komiya S, Hiraoka K, Zenmyo M, Morimatsu M and Inoue A: IL-6 in a pleomorphic type of malignant fibrous histiocytoma presenting high fever. Hum Pathol 29: 758-761, 1998.

20. Osaka S, Hayakawa S, Yoshida Y, Sakurada E, Ryu J and Sugitani M: Interleukin-8 producing malignant fibrous histiocytoma with prolonged fever. Acta Histochem Cytochem 39: 17-21, 2006.

21. Freifeld AG, Bow EJ, Sepkowitz KA, et al; the Infectious Diseases Society of America: Clinical practice guideline for the use of antimicrobial agents in neutropenic patients with cancer: 2010 update by the Infectious Diseases Society of America. Clin Infect Dis 52: e56-e93, 2011.

22. Kiyosawa T, Higaki H and Nakayama Y: Liposarcoma associated with fever and reversible hepatic dysfunction. Int $\mathrm{J}$ Dermatol 36: 132-134, 1997.

23. Chang JC: Antipyretic effect of naproxen and corticosteroids on neoplastic fever. J Pain Symptom Manage 3: 141-144, 1988.

24. Coussens LM and Werb Z: Inflammation and cancer. Nature 420: 860-867, 2002.

25. Mantovani G, Maccio A, Pisano M, et al: Tumor-associated lympho-monocytes from neoplastic effusions are immunologically defective in comparison with patients autologous PBMCs are capable of releasing high amounts of various cytokines. Int J Cancer 71: 724-731, 1997.

26. Nakanishi H, Yoshikawa K, Joyama S, et al: Interleukin-6/soluble interleukin-6 receptor signaling attenuated proliferation and invasion, and induces morphological changes of a newly established pleomorphic malignant fibrous histiocytoma cell line. Am J Pathol 165: 471-480, 2004.

27. Kathula SK, Shah K, Polenakovik H and Koduri J: Cyclo-oxygenase II inhibitors in the treatment of neoplastic fever. Support Care Cancer 11: 258-259, 2003.

28. Tsavaris N, Zinelis A, Karabelis S, Beldecos D, Bacojanis C, Milonacis N, Karvounis N and Kosmidis P: A randomized trial of the effect of three non-steroid anti-inflammatory agents in ameliorating cancer-induced fever. J Intern Med 228: 451-455, 1990. 